\title{
Studies on Preparation of Lysophospholipids from Soybean Phospholipids Using Lipozyme TL IM Immobilized Enzyme
}

\author{
SUMIT NANDI ${ }^{*}$ and RUPA BHATTACHARYYA
}

Department of Basic Science and Humanities (Chemistry), Narula Institute of Technology, Agarpara, Kolkata-700109, West Bengal, India

sumitnandi5@gmail.com

Received 1 February 2017 / Accepted 24 February 2017

\begin{abstract}
Soybean lysophospholipids (SBLPLs), produced from soybean phospholipids (SBPLs), are important cell signaling and growth factor molecules related to different cardiovascular functions. SBLPLs help to prevent different diseases like cancer and neurological disorders. It has considerable role in membrane chemistry and biochemistry and also in many physiological and pathological processes. In this investigation, SBLPLs were prepared from crude SBPLs which are a byproduct of soybean oil refinery industry. The methods adopted include deoiling of crude SBPLs and treating with butanol in hexane medium using 1,3- specific Lipozyme TL IM immobilized lipase from Thermomyces lanuginosus at $40{ }^{\circ} \mathrm{C}$. The final product contains significant amount of LPLs alongwith other phospholipids.
\end{abstract}

Keywords: Phospholipids, Lysophospholipids, Soybean oil, TL IM enzyme

\section{Introduction}

Phospholipids (PLs) are amphiphilic molecules mostly found in plant and animal cells. PLs are essential compounds in cellular membranes. PLs have many beneficial effects in our body. Dietary PLs are essential for preventing a range of human diseases such as coronary heart disease, cancer or inflammation ${ }^{1}$. PLs are important for optimal brain health by playing several roles in the brain. They not only determine the flow of minerals, nutrients and drugs into the cell but also influence the communication between brain cells directing the shape of receptors and promoting the growth of dendrites. Several studies have been made to show beneficial effects of PLs in tumor and metastasis inhibition ${ }^{2,3}$.

PLs are compounds made of two fatty acids attached to glycerol, the mineral phosphorous and an amine. LPLs are derivatives of PLs in which one or both acyl derivatives have been removed by hydrolysis (Figure 1). LPLs act as emulsifying and solubilising agents and used as synthetic intermediates which have application in foods, cosmetics, agrochemicals and pharmaceuticals ${ }^{4}$. Recently LPLs are used as a preferred 
carrier for docosahexaenoic acid to the brain ${ }^{5}$ which has anti-inflammatory effect on human body as well as for slowing down platelet activation ${ }^{6}$. LPLs exhibit a broad range of biological activities in their own right which is applied for the prevention of growing number of diseases, such as neuropathic pain, atherosclerosis, inflammation, cancer and obesity $^{7-10}$. SBLPLs have potential role as important ingredients in food for long term storage which are used to prevent unwanted colorization of food or any microbial contamination. SBLPLs are also used in protein purification and in agrochemicals as mild detergent and antifungal agent ${ }^{11}$.

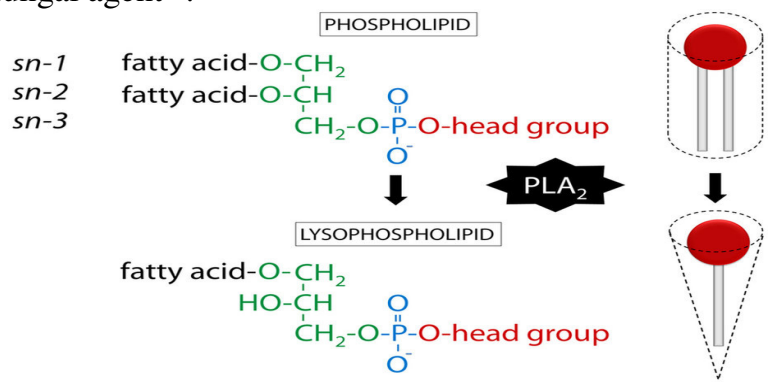

Figure 1. Phospholipids to lysophospholipids

LPLs can be synthesized by different chemical and enzymatic methods as reported in the literature. D-Mannitol ${ }^{12}$, glyceric acid using fluorenylmethylcarbonate ${ }^{13}$, $p$-nitrophenylglycerate ${ }^{14}$ are used by several researchers for the synthesis of LPLs using various chemical catalysts. D'Arrigo et al., ${ }^{15}$ also synthesized short/long chains glycerophosphocholines by chemical catalytic method. Researchers also used different enzymes for the synthesis of LPLs ${ }^{16-19}$ as enzymatic route has several benefits. Advantages of biocatalyst include specificity, thermo stability, mild reaction conditions in terms of low temperature and its environmental friendliness. But enzymatic route for the synthesis of SBLPLs from cheap raw materials is scarce. In the present study, focus of research has been concentrated for the preparation of SBLPLs from cheap raw material like SBPLs which is a by-product of rice bran oil refinery industry. Here, biocatalyst like 1, 3- specific Lipozyme TL IM immobilized lipase from Thermomyces lanuginosus is utilized in hexane medium with the help of butanol for this purpose maintaining a mild reaction temperature of $40{ }^{\circ} \mathrm{C}$.

\section{Experimental}

Raw material like crude SBPLs was collected from M/s. Sethia Oil Mills, Burdwan, West Bengal, India. The enzyme 1, 3-specific Lipozyme TL IM immobilized lipase from Thermomyces lanuginosus was a kind gift of Novozyme South Asia Pvt. Ltd. Bangalore, India with catalytic activity 75 Interesterification unit Novo/g (IUN/g). Butanol $(99.8 \%$ pure) and hexane were purchased from S.D. Fine Chemicals (Mumbai, India). Except otherwise specified all other chemicals used were A.R. Grade.

\section{Results and Discussion}

The content of oil, PL and fatty acid composition of crude SBPLs are depicted in Table 1. Crude SBPLs contains $60 \pm 0.437 \%$ oil and $35 \pm 0.213 \%$ PL. Regarding fatty acid composition, SBPL contains $25.2 \pm 0.138 \%$ palmitic acid, $2.8 \pm 0.019 \%$ stearic acid, $15.2 \pm 0.273 \%$ oleic acid, $51.2 \pm 0.475 \%$ linoleic acid and $4.5 \pm 0.010 \%$ linolenic acid. So SBPLs have higher amount of unsaturated fatty acids (nearly $71 \%$ ) compared to saturated fatty acids (nearly 28\%). In the first stage, deoiling of SBPLs is done by acetone fractionation 
and after deoiling, the composition of the deoiled SBPLs are determined by High performance liquid chromatography technique which is shown in Figure 2. It can be observed from the Figure that deoiled SBPLs contains higher amount of phosphatidylcholine (PC) or lecithin $(40.8 \%)$ and phosphatidylethanolamine (PE) (25.5\%) compared to phosphatidic acid (PA) (11.2\%) and phosphatidylinositol (PI) (14.4\%). But it contains negligible amount of phosphatidylserine (PS) (1.1\%).

Table 1. Analytical characteristics and fatty acid composition of crude SBPLs

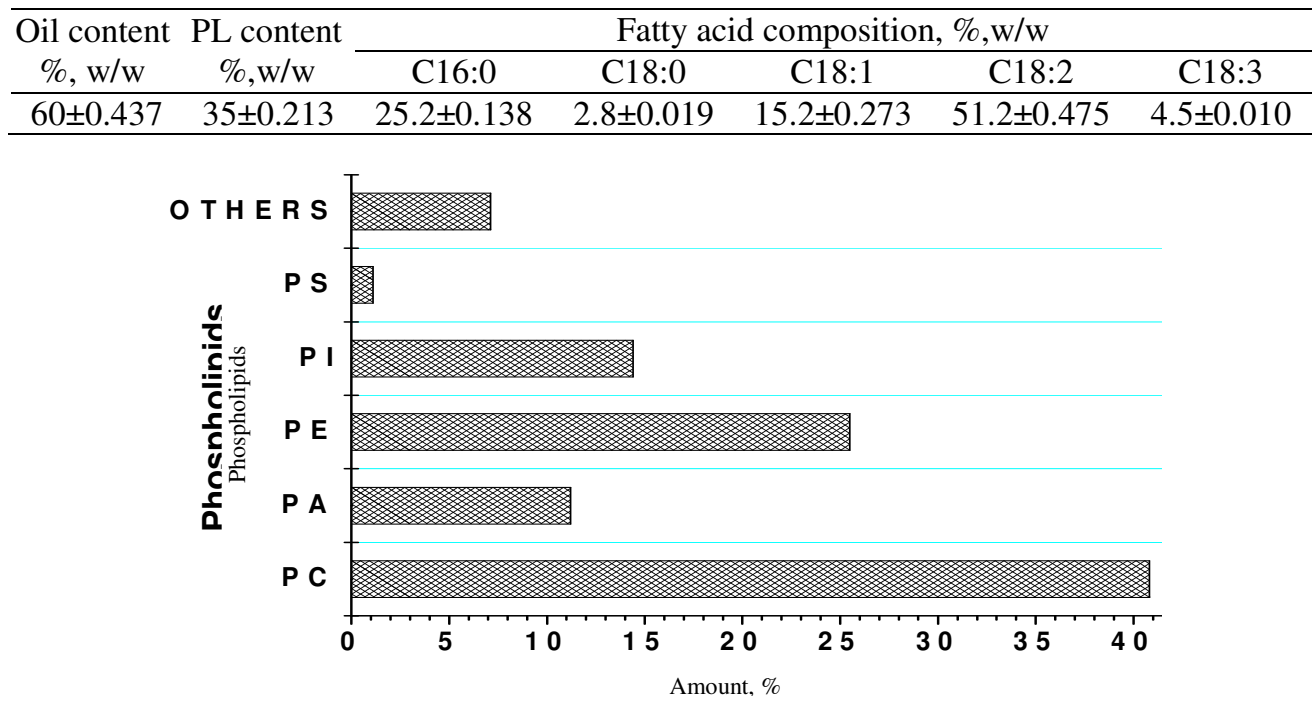

Figure 2. Composition of deoiled SBPLs (\%,w/w)

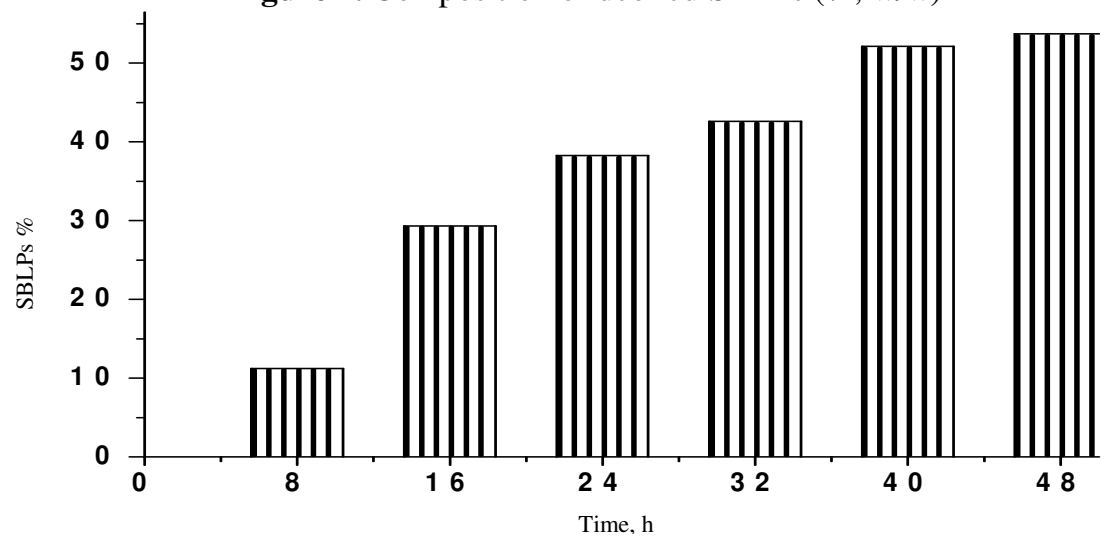

Figure 3. Rate of preparation of SBLPLs (Enzyme: TL IM-10\%, Temperature-40 ${ }^{\circ} \mathrm{C}$, Deoiled PL: Butanol-1:3, Time-48 h)

\section{Preparation of SBLPLS}

For the preparation of SBLPLs, deoiled PL was taken in hexane medium and then reacted with butanol (1:3 molar ratio) in the presence of 1,3- specific Lipozyme TL IM immobilized lipase $(10 \% \mathrm{w} / \mathrm{w})$ at $40{ }^{\circ} \mathrm{C}$. The reaction was continued for $48 \mathrm{hrs}$. After completion of reaction, the immobilized enzyme was separated by filtration and the product was recovered 
by acetone fractionation. Figure 3 shows the rate of preparation of SBLPLs and it has been observed that completion of alcoholysis reaction takes $45-48 \mathrm{~h}$ as after that no significant enhancement of reaction occurred. Figure 4 shows the composition of the product which indicates nearly $53.7 \%$ SBLPLs along with $16.1 \%$ PC, $7.1 \%$ PA, $15.3 \%$ PE and $6.9 \%$ PI. Table 2 shows the fatty acid composition of the product indicating $10.1 \pm 0.097 \%$ palmitic acid, $1.1 \%$ stearic acid, $10.9 \pm 0.103 \%$ oleic acid, $74.7 \pm 0.231 \%$ linoleic acid and $3.2 \pm 0.005 \%$ linolenic acid. In comparison with the original deoiled PL, linoleic acid content increased significantly in the SBLPLs (from $51.2 \%$ to $74.7 \%$ ) while palmitic acid, oleic acid and linolenic acid content decreased. Removal of fatty acids from 1, 3-positions in the deoiled PL may be the factors responsible behind it.

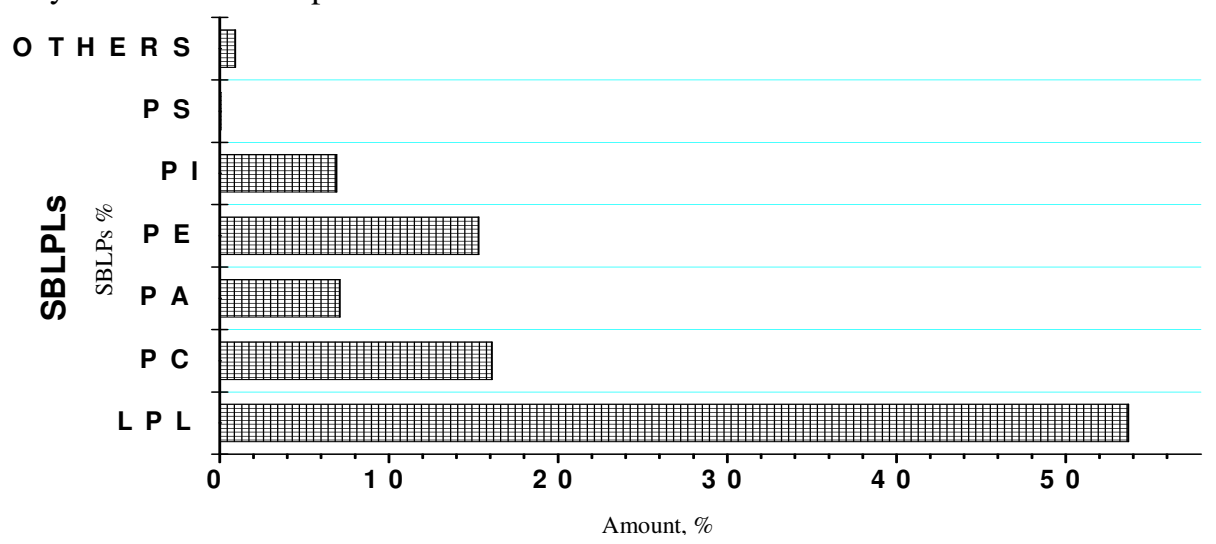

Figure 4. Composition of SBLPLs

Table 2. Fatty acid composition of SBLPLs

\begin{tabular}{ccccc}
\hline $\mathrm{C}_{16: 0}$ & $\mathrm{C}_{18: 0}$ & $\mathrm{C}_{18: 1}$ & $\mathrm{C}_{18: 2}$ & $\mathrm{C}_{18: 3}$ \\
\hline $10.1 \pm 0.097$ & $1.1 \pm 0.00$ & $10.9 \pm 0.103$ & $74.7 \pm 0.231$ & $3.2 \pm 0.005$ \\
\hline
\end{tabular}

In Table 3, the interfacial tension of SBPLs and SBLPLs against water at $27{ }^{\circ} \mathrm{C}$ in chloroform solution is indicated. This has been shown at six different concentrations. However, Table 5 reveals that interfacial tension of SBLPLs is somewhat less than interfacial tension of SBPLs at all concentration levels. The suitability of the process technology is depicted herewith.

Table 3. Interfacial tension (dynes/cm) against water at $27^{\circ} \mathrm{C}$ in chloroform medium

\begin{tabular}{ccccccc}
\hline Material & $0.5 \%$ & $0.4 \%$ & $0.3 \%$ & $0.2 \%$ & $0.1 \%$ & $0.05 \%$ \\
\hline SBPLs & $13.6 \pm 0.135$ & $16.1 \pm 0.085$ & $18.7 \pm 0.111$ & $21.9 \pm 0.101$ & $26.1 \pm 0.119$ & $28.3 \pm 0.149$ \\
SBLPLs & $12.1 \pm 0.061$ & $14.6 \pm 0.078$ & $17.2 \pm 0.108$ & $19.4 \pm 0.111$ & $24.8 \pm 0.103$ & $26.2 \pm 0.131$ \\
\hline \multicolumn{7}{c}{ Interfacial tension of chloroform against water at $27^{\circ} \mathrm{C}$ is 33.2 dynes/cm }
\end{tabular}

\section{Conclusion}

Technology for preparation of soybean lysophospholipids from cheap raw materials like soybean phospholipids is an innovative one. In the present study, crude soybean phospholipids, collected from soybean oil refinery industry, has been treated with butanol in the presence of 1, 3-specific Lipozyme TL IM immobilized lipase (Thermomyces lanuginosus). The most interesting fact here lies the possibility of reuse of enzyme which minimizes the cost of the process. Moreover, minimum temperature is beneficial for the identified process which is energy efficient. Reaction time is somewhat longer which encourages to find out more suitable biocatalyst for the process technology. The final product 
contains considerable amount of lysophospholipids which is also encouraging. The present enzymatic and energy efficient process may be applied for the synthesis of lysophospholipids from crude raw materials in pilot scale and in industrial sector of tomorrow.

\section{References}

1. Kullenberg D, Taylor L A, Schneider M and Massing U, Lipids Health Disease, 2012, 11, 3; DOI:10.1186/1476-511X-11-3

2. Sakakima Y, Hayakawa A, Nagasaka T and Nakao A, Hepatogastroenterology, 2009, 56(90), 481-484.

3. Hossain Z, Hosokawa M and Takahashi K, Nutr Cancer, 2009, 61(1), 123-130.

4. Dennis E A, Brown H A, Deems R A, Glass C K, Merrill A H, Murphy R C, Raetz C R H, Shaw W, Subramaniam S, Russell D W, VanNieuwenhze M S, White S H, Witztum J L and Wooley J, Functional lipodomics CRC Press: Boca Raton, FL, USA, 2006, 1-15.

5. Lagarde M, Bemoud N, Brossard N, Lemaitre D D, Thies F, Croset M and Lecerf J, $J$ Mol Neurosci., 2001, 16(2-3), 201-204; DOI:10.1385/JMN:16:2-3:201

6. Sontakke U B, Kaur H, Tyagi A K, Kumar M and Hussain A, Effect of feeding rice bran lyso-phospholipids and rumen protected fat on milk yield and milk composition in cross bred cows, Proceedings of Global Animal Nutrition Conference (GLANCE 2014), 20-22 April, 2014; DOI:10.13140/2.1.4819.6487

7. Kim K S, Sengupta S, Berk M, Kwak Y G, Escobar P F, Belinson J, Mok S C and Xu Y, Cancer Res., 2006, 66(16), 7983-7990; DOI:10.1158/0008-5472.CAN-05-4381

8. Sutphen R, Xu Y, Wilbanks G D, Fiorica J, Grendys E C, LaPolla J P J, Arango H, Hoffman M S, Martino M, Wakeley K, Griffin D, Blanco R W, Cantor A B, Xiao Y J and Krischer J P, Cancer Epidemiol Biomarkers Prev., 2004, 13, 1185-1191.

9. Zhao Z, Xiao Y, Elson P, Tan H, Plummer S J, Berk M, Aung P P, Lavery I C, Achkar J P, Li L, Casey G and Xu Y, J Clin Oncol., 2007, 25(19), 2696-2701; DOI:10.1200/JCO.2006.08.5571

10. Raynal P, Montagner A, Dance M and Yart A, Pathol Biol., 2005, 53(1), 57-62; DOI:10.1016/j.patbio.2004.01.005

11. Kim J, Lee C S, Oh J and Kim B G, Enzyme Microbial Technol., 2001, 29(10), 587592; DOI:10.1016/S0141-0229(01)00447-1

12. Xia J and Hui Y Z, Tetrahedron Asymmetry, 1997, 8(3), 451-458; DOI:10.1016/S0957-4166(97)00005-0

13. Bibak N and Hajdu J, Tetrahedron Lett., 2003, 44(31), 5875-5877; DOI:10.1016/S0040-4039(03)01419-9

14. Rossetto R, Bibak N and Hajdu J, Tetrahedron Lett., 2004, 45(41), 7371-7373; DOI:10.1016/j.tetlet.2007.08.024

15. D'Arrigo P, Fasoli E, Pedrocchi-Fantoni G, Rossi C, Saraceno C, Servi S and Tessaro D, Chem Phys Lipids, 2007, 147, 113-118; DOI:10.1016/j.chemphyslip.2007.03.008

16. Adlercreutz P, Lyberg A M and Adlercreutz D, Eur J Lipid Sci Technol., 2003, 105(10), 638-645; DOI:10.1002/ejlt.200300832

17. Kim I H, Garcia H S and Graham C, Enzyme Microb Technol., 2007, 40(5), 11301135; DOI:10.1016/j.enzmictec.2006.08.018

18. Sarney D B, Fregapane G and Vulson E N, J Am Oil Chem Soc., 1994, 71(1), 93-96; DOI:10.1007/BF02541478

19. Ulbrich-Hofman, Eur J Lipid Sci Technol., 2003, 105, 305-308; DOI:10.1002/ejlt.200390060 